\title{
Model of the omni-channel Interaction in the Web 4.0 environment
}

\author{
Anna Chernikova ${ }^{1}$, Sergey Krasnov ${ }^{1 *}$, and Sergey Sergeyev ${ }^{1}$ \\ ${ }^{1}$ Peter the Great St. Petersburg Polytechnic University, Institute of Industrial Management, \\ Economics and Trade, 195251, Politechnicheskaya st., 29, Russian Federation
}

\begin{abstract}
The practical implementation of the concept "Industry 4.0" entirely depends on the level of coordination between businesses, organizations and the entire group of consumers. The dominating comprehension of such interaction as a net of complex topology where nodes act as objects that have an interface a surface for contacts, results in a neuro-net-concept or the Web 4.0. Within the framework of the Russian national program "National Technological Initiative", the development of this direction is considered as one of the main priorities. The quality of implementation of the system interaction in this paradigm is greatly influenced by algorithms used in the cloud servers of the nodes included into the structure of the Web 4.0. Besides, operation of businesses in the conditions of global markets will take place in the situation of strict competition and solutions forming the basis of the software have to be based on the scientific approach with the use of the methods of optimization and mathematical models. As the competition in the commercial sphere turned into the contest between the economic efficiency of on-line platforms, this work proposes a particular implementation of the algorithm of omni-channel interaction formed on the basis of a mathematical model.
\end{abstract}

Interaction with the outer environment of every economical subject including both industrial plants and service organizations [1], as well as commercial wholesale and retail networks, can be evaluated using a lot of various reference values. The primary task of managers of these organizations consists in finding ways of the most efficient use of their business' potential, as well as covering the maximum number of consumers. The omnichannel interaction implements the front-edge technologies [2] of the digital economy. First of all, we should note the intrinsic possibility to work with large numbers of customers sometimes even with exact personality. Besides, we should take into consideration the possibility to use the entire history of the customer's preferences and purchases. This issue, as well as implementation of the technologies of targeted approach [3,4], make it possible to formalize the process of mutual influence of the basic indexes of the business performance and use a well-developed set of mathematical methods to take optimal decisions [5].

* Corresponding author: hsm.krasnov@gmail.com 
While selecting the strategy of interaction of the business in the Web 4.0 environment [6], it is, first of all, necessary to rely upon the development of information technologies, Internet networks, XaaS solutions [7], SIM solutions, search engines co-operation with advertising providers, aggregators' sites. Besides, we need to take into consideration the domination of integrated digital systems in the market. At the same time, online processing of any kinds of interactions [8], including payments, led to deep changes in the architecture of business in all the spheres. This was primarily made possible due to system integration of interaction models of corporative systems of CRM (Customer Relationship Management), ERP (Enterprise Resource Planning), as well as the operation [9] in the mode M2M (Machine-to-Machine). The growing role of online sales, the increased use of virtual sites has brought about the paradigm of omni-channel interaction. At the same time, the growing competition in the large network business environment puts forward the task to use all the management tools with maximum efficiency to communicate with the customers. Such activity is made still more difficult due to instability of the business environment [10]. Planning even for a period as short as 2-3 years ahead has become a serious task [11] that would require employing a DEA (Data Envelopment Analysis) method. This forms a basis for improving business processes, optimizing the corresponding surfaces of digital data, transform the methods of communication with the customers.

The proper transition to omni-channel interaction was only made possible due to development of both the Web 3.0 technologies and the combination of alternative channels making it possible to interact with the identified customers with consideration of their locations. The main part in this process was played by mobile applications having the maximum degree of convertibility and promotional activity. Today, in various business spheres, impressive results have been achieved in using omni-channel communication. In particular [12], the company Walt Disney Parks and Resorts Worldwide, Inc. specializing in tourism and recreation controls hotels, entertainment parks and sports complexes was able to integrate all the different communication channels into one digital system to communicate with both the existing and the prospective customers. At the same time, they also use the capabilities of customers' smartphones, the data of GPS-tracking, customers' authorization and other components [13] aimed at both loyalty enforcement and new customers' acquisition. Due to the fact that, at the current stage of business development, aimed at maximizing the number of customers [14], there is no alternative to omni-channel technology; methods need to be developed [15] that would make it possible to evaluate the economic efficiency of the created virtual platform [16] and the loyalty level of the identified customer. This will also make it possible to optimize the operating format and services matrix.

In this work we modelled the business segment and offered three variants of interaction with customers: advertising, presentations, market monitoring. Even though these kinds of activities were chosen conditionally, to a large extent, they reflect the largest expenditures in reality. As all the mathematical formulas are scalable, it is easy to increase the scale of the equations in the model [17] as defined through the number of arguments. Let us set the task, define the basic descriptors and introduce the corresponding notation.

Let us introduce formalism for the model of commercial activity comprising $S$ nodes (business branches). Before the beginning of the reporting period, the top managers approve the plans for the budget. It is necessary to consider all the possible investment variants. Basing on the analysis of the reports from the previous period and the statistics of the reports for similar commercial networks, it is known that, if an amount of money $v_{j}$ was invested in advertising or in the network branch with number $j$, where $j=1,2, \ldots, s$, the profit from such activity can be described by function $P_{j}\left(v_{j}\right)$. If an amount $w_{j}$ was invested into the relevant branches for presentations, the expected profit will be $Q_{j}\left(w_{j}\right)$. 
Monitoring of customers' market preferences, depending on the location of the branch $j$ as a network component, with the amount of investment $x_{j}$ will, in accordance with our investigation results, bring the future profit during the next reporting period according to the function $R_{j}\left(x_{j}\right)$. The budget of a branch depends on its size, turnover, distinctive matrix, the level of post-sale service. Correspondingly, the amount of financing for improving the interaction with customers is limited to the sum $L_{j}$, where $j=1,2, \ldots, s$. The consolidated budget for the entire set of measures for all the branches is also limited to the total $\operatorname{sum} N$.

It is necessary to distribute the investment in the optimal way [18] between the branches of the network and calculate their values for all the three directions. The criterion here is the maximum of the total profit of the commercial network. The marker limits are the maximum allowable expenditures $L_{j}$ and $N$.

In the formal way, this task can be recorded as the search for the maximum of the composite function of the kind: $\sum_{j=1}^{s}\left[P_{j}\left(v_{j}\right)+Q_{j}\left(w_{j}\right)+R_{j}\left(x_{j}\right)\right]$ in the presence of the set levels of the total amount of finance for the measures

$$
\sum_{j=1}^{s}\left(v_{j}+w_{j}+x_{j}\right) \leq N
$$

and the budget limit for branch number $j$ of the commercial network:

$$
\left(v_{j}+w_{j}+x_{j}\right) \leq L_{j}, j=1,2, \ldots, s .
$$

It also should be considered that the values $v_{j}, w_{j}, x_{j}$ have to fit the inequalities (the non-negativeness condition):

$$
v_{j} \geq 0 \quad, w_{j} \geq 0 \quad, x_{j} \geq 0 \quad \text { for all the values } j=1,2, \ldots, s
$$

While solving the equation, it is necessary to determine and formalize the uncertainty of functioning [19] of such complex economical object as a commercial network. This will make it possible to form algorithms to take managerial decisions, with the efficiency criteria [20] being the profit maximization.

This task belongs to the class of problems of discreet optimization [21]. One of the most universal methods of their solving is the dynamic programming method. In this particular case, completely plausible are both Bellman's principle and the possibility for consecutive analysis. Let us present the problem of budget selection as a concept of a discreet controllable system [22] and let us formulate the corresponding recurrent relations. The advantage of such approach to the problem is also the possibility to insert the obtained algorithm for searching the optimal solution into the well-spread CRM and ERP solutions that are the basis for the concept [23] "The Industry 4.0".

During the analysis of the formalized formulation of the problem, we can note that the limit (1) is imposed as a whole on all the arguments of the model, and the inequality (2) relates to the local sums of finance of the branch number $j$ of the commercial network.

To formulate the task in the terms of the dynamic programming, it is necessary to introduce notation $g_{j}(n)$ - the function of the profit maximum with the optimal distribution of the sum $n$ among $j=1,2, \ldots, s$ brunches in the network. Then we can record the recurrent relation of the dynamic programming as follows: 


$$
g_{j}(n)=\max \left[P_{j}\left(v_{j}\right)+Q_{j}\left(w_{j}\right)+R_{j}\left(x_{j}\right)+g_{j-1}\left(n-v_{j}-w_{j}-x_{j}\right)\right]
$$

where $j=1,2, \ldots, s$ and the notation $n=0,1,2, \ldots, N$ is adopted, and only non-negative integer values $v_{j}, w_{j}, x_{j}$ participate the optimization, and they correspond the limiting inequality $\left(v_{j}+w_{j}+x_{j}\right) \leq \min \left(L_{j}, n\right)$.

Further on, to solve the multidimensional optimization task [24], we will transform the obtained equations of the mathematical models. We can present these equations as a search for the maximum of the sum:

$$
P_{j}\left(v_{j}\right)+Q_{j}\left(w_{j}\right)+R_{j}\left(x_{j}\right)
$$

On condition that the following limitation is observed:

$$
\left(v_{j}+w_{j}+x_{j}\right) \leq y
$$

and the non-negativeness $v_{j}, w_{j}, x_{j}$ among the values of the natural row of numbers.

We will search for the solution for each value of the auxiliary variable $y$ that can take values: $y=0,1, \ldots, L_{j}$. Then we can introduce the function

$$
p_{j}(y)=P_{y}\left(y_{j}\right), y=0,1, \ldots ., L_{j}
$$

and apply the recurrent method to the task $(5,6)$. We will transform (4) into the form:

$$
g_{j}(y)=\max _{w_{j}}\left[Q_{j}\left(w_{j}\right)+p_{j}\left(y-w_{j}\right)\right], y=0,1, \ldots ., L_{j}
$$

where the search of the optimal solution will be carried out only by the values $w_{j} \leq y$, and the condition:

$$
r_{j}(y)=\max _{x_{j}}\left[R_{j}\left(x_{j}\right)+q_{j}\left(y-x_{j}\right)\right], y=0,1, \ldots ., L_{j}
$$

The result will be the value $p_{j}(y)$ from (7) and (8) for each $j$ in the process of the search for $q_{j}(y)$. Accordingly, for the values $r_{j}(y)$ under $y=0,1, \ldots, L_{j}$, the search will be carried out by the values of the functions $q_{j}(y)$ and the condition (9). We will transform (4) and the result will be obtained from the solution of the ratio: $g_{j}(n)=\max _{y}\left[r_{j}(y)+g_{j-1}(n-y)\right], \quad j=1,2, \ldots, s, \quad$ where $n=, 1, \ldots, N$. The additional condition is that: $y \leq \min \left(L_{j}, n\right)$ under $j=1,2, \ldots, s$.

The obtained solution to the task can be spread over a wider class of problems arising in the actual commercial activity [25]. For example, one can register the seasonal character of such parameters as the demand, the revenue and the profitability. The described method $\mathrm{pf}$ dynamic programming will entirely apply also for the case when the limiting function is non-linear [26].

Despite that the above-listed equations are complex, the practical use of the described algorithm is pretty simple. It is only necessary to insert the budget limitations taken from the previous reports [27] and the influence of expenditures on the basic indexes of branches' profitability in the commercial network. Other calculations are carried out on computers using wide-spread sets of applications [28]. For solving non-linear tasks we also need the data on the demand for the product depending on the season and the data on the 
social-demographic landscape and specialization [29] of the branches and enterprises in the network.

Operation of the enterprises with the use of the concept "The Industry 4.0" requires transition to the new way of thinking based on the synthesis of artificial intelligence systems, machine-to-machine interaction with the use of all the available digital platforms. The criterion remains to be the economic efficiency, but the target will be achieved by using complex algorithms based on mathematical models and scientific methods of optimization. This paradigm brings about new tactics of interaction with customers, when modern approaches of incremental influence of large numbers of customers replace the old tactics of downward communication. Integration of business with social networks, geotargetting, cross-functional management and work with identified customers - these are merely a part of the entire digital environment. Even this simple example of omni-channel interaction makes it possible to state that, if there is a critical mass of customers incorporated in the Web 4.0 network, the classical "Sales funnel" can get a negative decrement, which is highly impossible without using digital economy methods.

Russia, as an influential participant of the world industry, has all the capabilities to promote the concept "The Industry 4.0" using such advantage as availability of scientific personnel in various branches of industry. It is necessary to employ innovative principles of work with the customers. The highly increased role of digital interaction conditioned by penetration of online portals and social networks requires accumulation of innovations.

Virtual presence in Internet applications, presence of ratings based on customers' feedback will inevitably lead to solving the task of optimizing economic indexes. The newly developed mathematical model can be especially well employed in the environment of the network commerce as it is easily scalable. At the same time, such important marketing parameters of omni-channel interaction as customer identification, customer's location consideration, the data set on the relationships history, are actually formalized only within the framework of program algorithms superimposed on the capabilities of the Web 4.0. It is the scientifically substantiated calculations based on stochastic algorithms that will make it possible to obtain a competitive advantage and optimize the basic economic indexes.

\section{References}

1. V. V. Glukhov, E. Balashova, Lecture Notes in Computer Science (including subseries Lecture Notes in Artificial Intelligence and Lecture Notes in Bioinformatics), 9247 (2015)

2. A. N. Tsatsulin, A. V. Babkin, N. I. Babkina, Proceedings of the 28th International Business Information Management Association Conference - Vision 2020: Innovation Management, Development Sustainability, and Competitive Economic Growth (2016)

3. S. M. Sergeev, Proceedings of the VIII International Conference (2015)

4. S. G. Bozhuk, A. S. Krasnov, International Conference "Quality Management, Transport and Information Security, Information Technologies", (IT\&QM\&IS-2017) DOI: 10.1109/ITMQIS.2017.8085790 (2017)

5. A. V. Babkin, T. J. Kudryavtseva, Modern Applied Science, 9(1) DOI: 10.5539/mas.v9n1p109 (2015)

6. Neuroweb [online] Available at: http://www.globalneuroweb.org/ru/ (2018)

7. T. Shchukin Neuronet: the next generation communication environment, Technowars. 5, (2014)

8. S. M. Sergeev, News of the Institute of Mathematics and Informatics, Udmurt State 
University, 1, 73 (2012)

9. A brief history of digital marketing technology,kapost.com, Retrieved 8 February (2017)

10. A. V. Babkin, V. A. Plotnikov, S. V. Muraveva, Proceedings of the 25th International Business Information Management Association Conference - Innovation Vision 2020: From Regional Development Sustainability to Global Economic Growth, IBIMA 2015 (2015)

11. Juha Karvanen, Ari Rantanen, Lasse Luoma, Survey data and Bayesian analysis: a cost-efficient way to estimate customer equity, Quantitative Marketing and Economics, 12 (3) (2014)

12. The Walt Disney Company [online] Available at: http://disneyparks.disney.go.com (2017)

13. B. Park, L. Simar and V. Zelenyuk, Categorical data in local maximum likelihood: theory and applications to productivity analysis, Journal of Productivity Analysis, $\mathbf{4 3}$ (2) (2015)

14. S. M. Sergeev, Innovations, 3(173) (2013)

15. S. M. Sergeev, Proceedings of the VII International Conference, Voronezh (2014)

16. Hermann, Pentek, Otto: Design Principles for Industrie 4.0 Scenarios (accessed on 4 May 2016) (2016)

17. S. M. Sergeev, Selected Papers of the International Scientific School "Paradigma" Winter-2016 (Varna, Bulgaria) (Yelm, WA, USA, 2016)

18. S. V. Krasnov, S. M. Sergeev, N. V. Mukhanova, A. N. Grushkin, Infocom Technologies and Optimization (Trends and Future Directions) 6th International Conference ICRITO, (2017)

19. "CRM in Customer Service", CRM Magazine, (Retrieved 22 November 2015)

20. E. Abushova, E. Burova, S. Suloeva, Lecture Notes in Computer Science (including subseries Lecture Notes in Artificial Intelligence and Lecture Notes in Bioinformatics), 9870 LNCS DOI: 10.1007/978-3-319-46301-8_7 (2016)

21. B. Wahba, The Fluff Cycle (And How to End It By Solving Real Sales and Marketing Problems), Strategy Science, Inc., (2012)

22. S. M. Sergeev, Cross-functional management in stochastic planning, Economics and management of control systems, 8(2.1) (2013)

23. D. Lavrova, A. Pechenkin, V. Gluhov. Applying correlation analysis methods to control flow violation detection in the internet of things, Source of the Document Automatic Control and Computer Sciences, 49 (8), DOI: 10.3103/S0146411615080283 (2015)

24. S. M. Sergeev Expansion of DEA methodology on the multimodal conception for the 3PL , Proceedings of the XXIII-the International Open Science Conference (Yelm, WA, USA, January 2018). Science Book Publishing House. Yelm, WA, USA, (2018)

25. G. Kleyner, A. Babkin, Lecture Notes in Artificial Intelligence and Lecture Notes in Bioinformatics), 9247. DOI: 10.1007/978-3-319-23126-6_50 (2015)

26. S. M. Sergeev, Selected Papers of the International Scientific School "Paradigma" (Summer-2015, Varna, Bulgaria) Compiling Editor Dr.Sc., Prof. E.Sibirskaya. Yelm, WA, USA, 38-41 (2015)

27. H. Kagermann, W. Wahlster and J. Helbig, (eds.),: Recommendations for implementing the strategic initiative Industrie 4.0, Final report of the Industrie 4.0 Working Group 
(2013)

28. V. V. Glukhov, I. V. Ilin, A. I. Levina, Lecture Notes in Computer Science (including subseries Lecture Notes in Artificial Intelligence and Lecture Notes in Bioinformatics), 9247, DOI: 10.1007/978-3-319-23126-6_47 (2015)

29. T. Malinina, V. Murina, Proceedings of the 8th International Scientific Symposium on Electrical Power Engineering, Electroenergetika (2015) 